\title{
El Movimiento pro-Emancipación de las Mujeres de Chile [MEMCH]. Desarrollo de una política integral y formas de educación popular para el reconocimiento de los derechos de las mujeres, 1935-1941
}

Resumen: El artículo analiza las visiones de la política y las formas de educación del Movimiento pro-Emancipación de las Mujeres de Chile [MEMCH] en el periódico La Mujer Nueva entre 1935-1941. El movimiento elaboró una perspectiva integral de la política para ampliar la democracia representativa desde el género y consolidar una justicia absoluta para las trabajadoras, así como el reconocimiento de las mujeres como sujetos políticos. Para ello, desarrolló diversas estrategias de educación popular como la ampliación de la educación primaria para mujeres trabajadoras, intervenciones educativas territoriales y la promoción de formas de autoeducación para la construcción de identidades al interior del movimiento.

Palabras clave: movimiento feminista, historia de la educación, prácticas de educación.

\section{Movement for the Emancipation of Women in Chile [MEMCH]. The Development of comprehensive politics and forms of popular education for the recognition of women's rights, 1935-1941}

Abstract: The article analyzes the views of politics and the education strategies of the Pro-Emancipation of Women of Chile Movement [MEMCH], as seen through the newspaper La Mujer Nueva, between 1935-1941. The movement developed a comprehensive perspective on politics, aiming to broaden representative democracy from a gender perspective, to consolidate absolute justice for women workers, and the recognition of women as political subjects. To do this, the movement developed various popular education strategies such as the expansion of primary education for working women, territorial educational interventions and the promotion of forms of self-education for the construction of identities within the movement.

Keywords: feminist movement, history of education, education practices.

\section{Movimento pela Emancipação das Mulheres do Chile [MEMCH]. Desenvolvimento de uma política integral e formas de educação popular para o reconhecimento dos direitos das mulheres, 1935-1941} Resumo: 0 artigo analisa as visões da política e as formas de educação do Movimento pela Emancipação das Mulheres do Chile [MEMCH] no jornal La Mujer Nueva entre 1935-1941. 0 movimento elaborou uma perspectiva integral da política para ampliar a democracia representativa de gênero e consolidar justiça absoluta para as trabalhadoras, bem como o reconhecimento das mulheres como sujeitos políticos. Para tanto, desenvolveu diversas estratégias de educação popular como a ampliação da educação primária para mulheres trabalhadoras, intervenções educativas territoriais e promoção de formas de autoeducação para a construção de identidades dentro do movimento.

Palavras-chave: movimento feminista, história da educação, práticas educacionais.

Cómo citar este artículo: Claudia Montero Miranda y Graciela Rubio Soto, "El Movimiento pro-Emancipación de las Mujeres de Chile [MEMCH]. Desarrollo de una política integral y formas de educación popular para el reconocimiento de los derechos de las mujeres, 1935-1941”, Trashumante. Revista Americana de Historia Social17 [2021]: $174-197$.

DOI: 10.17533/udea.trahs.n17a08

Fecha de recepción: 5 de abril de 2020

Fecha de aprobación: 3 de septiembre de 2020

Claudia Montero Miranda: Doctora en Estudios Latinoamericanos por la Universidad de Chile. Profesora titular del Instituto de Historia y Ciencias Sociales de la Universidad de Valparaíso. ORCID: 0000-0001-5209-0931. Correo electrónico: claudia.montero@uv.cl

Graciela Rubio Soto: Doctora en Educación por la Universidad de Granada. Profesora titular del Instituto del Instituto de Historia y Ciencias Sociales de la Universidad de Valparaíso. ORCID: 0000-0002-4849-835X

. Correo electrónico: graciela.rubio@uv.cl 


\section{El Movimiento pro-Emancipación de las Mujeres de Chile [MEMCH]. Desarrollo de una política integral y formas de educación popular para el reconocimiento de los derechos de las mujeres, 1935-1941}

Claudia Montero Miranda y Graciela Rubio Soto

Introducción

En el número 25, de septiembre de 1940, del periódico La Mujer Nueva, órgano Cde difusión del Movimiento pro-Emancipación de las Mujeres de Chile $(\mathrm{MEMCH})$, se leen unas notas sobre el analfabetismo y la existencia de una escuela para adultas coordinada por el Comité pro-Cultura Popular de la organización. Durante el mismo año, una actividad de reflexión nacional había constatado los altos niveles de analfabetismo y sus efectos específicos en las mujeres. Por ello, el Comité había asumido como imperativo de acción crear esta escuela para adultas en la que se enseñaría lectura, escritura y aritmética y, además, algunos oficios. La iniciativa se enmarcaba en una política general del movimiento que buscaba, distante de una orientación asistencialista, mostrar a la mujer proletaria la ceguera en la que estaba sumida y "ayudarla a su liberación".

La propuesta formaría parte de una visión compleja de la educación desarrollada por el movimiento que anclada en una visión integral de la política pretendía ampliar las formas de justicia desde la perspectiva de las mujeres. Se ha analizado poco cómo el movimiento feminista pensó integralmente la relación entre política y educación. Abordar estos aspectos permite nutrir las perspectivas contemporáneas del movimiento feminista en Chile y del mundo que ha salido con fuerza a denunciar desigualdades históricas de género y a demandar justicia.

El propósito del artículo es analizar las visiones de la política y las formas de educación presentes en el discurso del MEMCH en la revista La Mujer Nueva en el periodo 1935-1941. Específicamente buscamos identificar los ámbitos de la política que el movimiento vinculó con educación y describir las estrategias implementadas. Postulamos que este promovió una visión integral de la política

* Este artículo forma parte del proyecto Fondecyt Regular 1210431.

1. Antonieta Alberti de Leiton, "Una visita a la Escuela de Adultas", La Mujer Nueva (Santiago) septiembre de 1940: 4. 
basada en las demandas del feminismo y en las experiencias históricas de desigualdad de las mujeres. Orientada hacia la ampliación de la democracia representativa en construcción y basada en el reconocimiento de las mujeres como sujetos políticos y sociales. ${ }^{2}$ Esta visión política integró dos estrategias educativas. La primera, discutir sobre educación como una función social para resolver las desigualdades específicas de la cuestión social en las mujeres, asociadas a los problemas de infancia, trabajo, maternidad y vida conyugal. La segunda, implementar un conjunto de formas de educación popular para consolidar el movimiento feminista a través de la ampliación de la educación primaria para mujeres trabajadoras, el desarrollo de intervenciones educativas territoriales y la promoción de formas de autoeducación para la construcción de identidades al interior del movimiento.

\section{El MEMCH y La Mujer Nueva}

En mayo de 1935 Elena Caffarena y Marta Vergara hicieron el llamado a fundar el MEMCH al que respondió un amplio número de mujeres que participaron en el acto fundacional en un salón de la Universidad de Chile. Su objetivo era luchar por los derechos y bienestar de las mujeres desde el feminismo y con autonomía de todo partido político. El movimiento organizado a partir de una dirección nacional, compuesta por mujeres alfabetizadas, profesionales y obreras en las que destacaban las docentes primarias, realizaba asambleas semanales en la capital y contaba con comités locales a lo largo de Chile. La instancia que congregaba a la totalidad de las integrantes fue el Congreso Nacional del que se realizaron dos versiones (1937 y 1940) en el periodo de estudio. ${ }^{3}$ Complementada con mítines, concentraciones y conferencias en las que solían llenar teatros y ocupar las calles, esta organización conformó prácticas militantes y organizativas articuladas con formas de educación política e ideológica. ${ }^{4}$

Sin duda, el MEMCH fue una organización pionera en América Latina, la más importante de Chile, de carácter interclasista, democrática, antifascista, internacionalista y pluripartidista. Se basaba en un feminismo radical para su época que significaba la defensa de los derechos de las mujeres en función de la exclusión social por el hecho de ser mujer; así como emancipación política, social, económica y cultural. Definió con convicción que la única forma de hacer efectiva sus demandas era que las propias mujeres asumieran su defensa. Si bien apoyaron a los conglomerados de centroizquierda, ${ }^{5}$ cuestionaron los supuestos de los partidos que entendían la emancipación de las mujeres como resultado de una liberación social

2. Axel Honneth, Reconocimiento y menosprecio. Sobre la fundamentación normativa de una teoría social (Madrid: Katz Editores / Centro de Cultura Contemporánea de Barcelona, 2010).

3. Posteriormente se realizarían congresos provinciales para participar en los congresos nacionales de mujeres en 1944 y 1947.

4. Corinne Antezana-Pernet, El MEMCH hizo historia (Santiago: Imprenta SEIT, 1997) 123.

5. La articulación con partidos políticos como el Partido Comunista fue en el espíritu de las alianzas antifascistas de entreguerras, debido a que el fascismo fue un férreo opositor al feminismo. 
mayor dado que consideraban que ese postulado escondía la indiferencia de los hombres ante la sujeción histórica de las mujeres. ${ }^{6}$

La Mujer Nueva fue el gran órgano de difusión del movimiento y una estrategia para su consolidación y autoformación. ${ }^{7}$ La publicación formaría parte de la llamada "prensa política de mujeres" y disputó un lugar en el espacio público en contextos de exclusión de género. ${ }^{8}$ Como prensa alternativa, siguiendo a Mirta Lobato, aportó a la construcción de las identidades de los sectores excluidos. En conjunto con otras publicaciones similares conformó un espacio de comunicación para públicos subalternos, con lo que expresaba la disidencia social y aportaba a contra informar, o a informar desde la perspectiva de los excluidos; fundamentalmente, a educar a través de una "docencia militante" o "pedagogía revolucionaria". De tal forma, La Mujer Nueva insertó al espacio público el discurso feminista del MEMCH denunciando las desigualdades que vivían las mujeres por su condición de género en todos los planos: sociales, económicos, legales, educativos, políticos, etcétera. Ello implicaba la mirada integral de la política.

\section{Los caminos para una política integral y una democracia liberal de reconocimiento}

"Por el grado de emancipación de la mujer se mide como en un termó-
metro, el grado de emancipación de los pueblos".

La Mujer Nueva (Santiago) noviembre de 1936: 2.

El MEMCH se desarrolló en un contexto que había heredado los efectos de la crisis política y económica de la década de 1920, en el cual diversos movimientos sociales de centro e izquierda habían propugnado el fin del Estado oligárquico decimonónico y desarrollado iniciativas para la ampliación de la representación social y la participación política. Caracterizarían al periodo (1930-1940) como de avances parciales en materia de leyes laborales sectoriales, así como marcado por la inflación y el encarecimiento de las subsistencias que provocó profundos problemas sociales. Luego del impacto de la crisis de 1929 en la economía exportadora, emergía un Estado inestable por los golpes de estado, tensionado por los efectos políticos y sociales de la dictadura de Carlos Ibáñez del Campo y demandado por los partidos de centro izquierda por institucionalizar los derechos sociales y la igualdad negada por los sectores oligárquicos. El sistema liberal en el segundo

6. Antezana-Pernet 51-62.

7. Un análisis de La Mujer Nueva en Claudia Montero, Y también hicieron periódicos. Cien años de prensa de mujeres en Chile 1850-1950 (Santiago: Hueders, 2018).

8. Montero.

9. Mirta Zaida Lobato, La prensa obrera. Buenos Aires y Montevideo, 1890-1958 (Buenos Aires: Edhasa, 2009). 
gobierno de Arturo Alessandri (1932-1938), ${ }^{10}$ orientado por una "restauración institucional" de derecha, impondría políticas gubernamentales de control sobre el movimiento obrero y social para lo que recurrió a formas institucionales de violencia como las milicias republicanas, mezcla de militarismo y civilismo, ${ }^{11}$ y al estado de excepción para la regularización del orden constitucional establecido en 1925 sin asegurar su democratización. ${ }^{12}$

Estos problemas nacionales se relacionaron con el contexto internacional de emergencia de los fascismos, la guerra civil española y el panamericanismo, entre otros, y, de esta manera, aportaron recursos experienciales, referentes ideológicos y argumentos para una discusión política de alta intensidad entre los agentes políticos y sociales. Simultáneamente, la prolongación de la crisis del Estado oligárquico decimonónico y la pugna por la integración de los referentes sociales y políticos de la democracia representativa se implicarían en el llamado Estado de compromiso en ciernes, con las propuestas de desarrollo enmarcadas en la industrialización sustitutiva de importaciones. ${ }^{13}$ Ya a inicios de la década de 1940 los gobiernos enfrentaron constantes déficits fiscales de la economía exportadora y la oposición de la derecha parlamentaria para ampliar las cuotas de igualdad en el sistema educativo. Por ejemplo, se retrasaba la implementación a cabalidad de la ley de instrucción primaria obligatoria dictada en 1920, el apoyo a la prevalencia de la educación sexista y la resistencia a financiar proyectos territoriales de educación campesina, entre otros. ${ }^{14}$

En un contexto sin total resguardo de los derechos individuales y de desconocimiento de los derechos sociales, el MEMCH promovió una visión integral de la política que desde los principios de igualdad y justicia para las mujeres, articuló aspectos invisibilizados de la cuestión social, los cuales destacaban las contradicciones y omisiones que consolidaban las desigualdades de género. Abordaron las relaciones entre salud, maternidad y trabajo desde una perspectiva económica y de derechos específicos del género tanto en la vida civil, el

10. María Angélica Illanes, “Ausente, señorita”. El niño chileno, la escuela para pobres y el auxilio 18901990 (hacia una historia social del siglo XX en Chile) (Santiago: Junta Nacional de Auxilio Escolar y Becas, 1991).

11. Verónica Valdivia Ortiz de Zárate, La milicia republicana. Los civiles con armas, 1932-1936 (Santiago: Dirección de Bibliotecas, Archivos y Museos, 1992).

12. Mario Garcés, El movimiento obrero y el Frente Popular (1936-1939) (Santiago: LOM Ediciones, 2018).

13. Rodrigo Henríquez Vásquez, En "estado sólido". Políticas y politización en la construcción estatal. Chile, 1920-1950 (Santiago: Ediciones Pontificia Universidad Católica de Chile, 2014); Tomás Moulian, Fracturas. De Pedro Aguirre Cerda a Salvador Allende (1938-1973) (Santiago: LOM Ediciones / Universidad ARCIS, 2006).

14. Graciela Rubio y otros, "La experimentación pedagógica territorial y la democratización del sistema educativo. Lecciones del Plan Experimental de Educación Rural de San Carlos (1944-1947)", Ensaio: Avaliação e Políticas Públicas em Educação 27.102 (2019): 88-107. DOI: 10.1590/s0104-40362018002701488. 
matrimonio y la vida conyugal, ${ }^{15}$ así como la educación infantil y de mujeres como función para la transformación social, entre otras. Discutían sobre estos temas (ya abordados por sus predecesoras) a través de un vínculo activo entre la política pública, los partidos de centro izquierda y los diversos movimientos sociales. La transformación social desde una perspectiva de género se sustentaba en el reconocimiento de las mujeres como sujeto político y ponía en el centro sus desigualdades, sus condiciones de vida, sus derechos civiles y sociales, además de la igualación de los salarios, como parte de su proceso de emancipación. ${ }^{16}$

Eulogia Román, en 1936, enfatizaba sobre la doble explotación de la mujer obrera al recibir un salario inferior a los hombres y al sufrir prácticas discriminatorias y sexistas en contextos laborales (ser despedida por embarazo y el no cumplimiento de la ley vigente sobre las contrataciones). La mirada desde el género reconocía relaciones sociales desiguales en las que se intersectaban ámbitos de clase y género-sexual. Era oprimida la clase obrera y doblemente las mujeres obreras y de otras clases sociales. En esta línea, en febrero del mismo año, María Vera comentaba la exposición de la delegada del movimiento en la Conferencia Internacional del Trabajo realizada en Ginebra y hacía hincapié en la necesidad de luchar por una "justicia absoluta", entendida como el reconocimiento de la igualdad de salario entre hombres y mujeres y la activación de los derechos sociales para las mujeres proletarias:

ellas saben y nosotras también que las Conferencias del Trabajo no hacen nada y no quieren hacer nada por mejorar nuestra situación [...] Hemos sostenido en nuestro programa el principio de justicia absoluta. A igual trabajo, igual salario. Nuestra compañera ha demostrado que a pesar de estar establecido en los Convenios Internacionales es letra en el papel. Defendió el cumplimiento de las leyes que establecen el salario íntegro para las mujeres embarazadas, proponiendo una moción que fue rechazada, decía: "La mujer no podrá ser separada de su trabajo desde el primer mes de embarazo hasta un año después" (sabemos cómo los patrones despiden a la mujer embarazada). Obrera, ayuda a nuestra labor, hazte digna del momento histórico que te tocó vivir, tienes una responsabilidad ante el futuro debes cumplir tu misión. Camarada mujer del proletario obrero nosotros te decimos: que el grito de nuestra compañera va a caer en el vacío si tu no luchas por nuestra situación [...] Madre-mujer, las generaciones del futuro te pedirán cuenta de tu decisión en el momento presente. ${ }^{17}$

El tono de seguridad con el que dan cuenta de la demanda refuerza la idea de justicia absoluta planteada. El llamado a las obreras a asumir con firmeza y sin vacilación la exigencia de derechos consagrados muestra, por una parte, el principio de la autonomía de las mujeres en la acción política y, por otra, que la diferencia de

15. Véase "Programa del Movimiento Pro Emancipación de las Mujeres", La Mujer Nueva (Santiago) noviembre 1935: 3

16. Honneth.

17. María Vera, "Ecos de la Conferencia Internacional del Trabajo", La Mujer Nueva (Santiago) febrero de 1936: 4. 
género que determinaba peores condiciones de vida para las mujeres se perpetuaba incluso si existían leyes compensatorias. De esta manera, la idea de justicia absoluta incluía tanto la demanda por una legislación justa como la denuncia para su cumplimiento y el llamado a que las mujeres activaran su defensa. Diversos escritos articularon estas discusiones en términos auto educativos. Por una parte, se explicaba el significado de la Conferencia Panamericana celebrada en Chile en 1936 y se relacionaba el evento con la historia del movimiento obrero, la actualidad y la política internacional. Su evaluación evidenció el incumplimiento de los acuerdos tomados por el gobierno en dicha conferencia:

El análisis de la situación nos deja una experiencia: que no tiene ninguna importancia obtener acuerdos si los grupos interesados en esos beneficios no están vigilantes para hacerlos cumplir. Diez años de legislación social encuentran a las mujeres chilenas más abandonadas y miserables que nunca, porque la masa obrera femenina no sabe ni se atreve a luchar por mejorar sus condiciones. Hoy que se están discutiendo en la Conferencia Panamericana las condiciones de trabajo de la mujer ¿por qué la obrera no concierta reuniones para informar o informarse sobre ellos? ¿Por qué no adhiere a los trabajos que está realizando el Movimiento pro Emancipación con este objeto? Nuestras reuniones de los días viernes [...] le pueden servir de orientación y ayuda si ella requiere preocuparse de sus condiciones económicas y sociales. Para nosotras la presencia de las obreras es el mejor estímulo y la mayor alegría. ${ }^{18}$

En este caso, la ira por la denuncia se combina con un tono acogedor que implica el llamado a la educación, el cual tenía una hora y lugar convertido en acción. El incumplimiento de las leyes y la falta del resguardo de estas por el Estado para el reconocimiento de las mujeres trabajadoras sería una deuda pendiente aún hacia 1940. Del mismo modo, en el inserto "Lo que no se exhibiría en Valparaíso" (1936) polemizaron con una actividad cultural coordinada por la Unión Femenina de Chile (organización conservadora de mujeres), que realizaría una exposición de manualidades hechas por mujeres para el centenario de la ciudad. El MEMCH usando la ironía criticó la actividad, la calificó como inútil por falta de sentido social, inscrita en una cultura de consumo y de reproducción de las desigualdades y roles sexistas. Además, contrapuso la crítica a la explotación de las mujeres que realizaban el trabajo remunerado. Así expuso ante la actividad de la Unión Femenina: "Mientras la acción bordea la lucha, podemos prescindir de ello, pero si la penetramos, la unión se hace forzosa ya que no hay en Chile ningún organismo lo suficientemente fuerte como para llevarnos solo a la victoria". ${ }^{19}$ Se confrontaba la visión hegemónica de la mujer productora de manualidades y reproductora del orden social con la que experimentaba las desigualdades sociales y el desconocimiento como sujeto político autónomo por el Estado.

18. María Aracil, “¿Qué es la Conferencia Panamericana?”, La Mujer Nueva (Santiago) enero de 1936: 1.

19. "Lo que no se exhibiría en Valparaíso", La Mujer Nueva (Santiago) julio de 1936: 1. 
Por último, si bien estaban conscientes de que el capitalismo no había liberado de la subordinación a las mujeres, este sí había propiciado junto con el liberalismo su inserción en la discusión pública y en el trabajo remunerado. Posición que las diferenciaba de los partidos y movimientos de izquierda.

Desde un enfoque integral de la política educativa cuestionaron la implementación de la Ley de Instrucción Primaria Obligatoria (1920), la cual consideraban que debía articularse con el aseguramiento de las condiciones de vivienda, salud y alimentación de los niños y niñas, y con un salario digno para sus madres. Promovieron una relación entre la política educativa y la protección social para asegurar el desayuno escolar al niño (en sentido genérico) ya que este no "podía nutrirse de palabras o sistemas pedagógicos". Por ello, iniciaron campañas tendientes a movilizar a las mujeres y a la clase política para dictar leyes de protección social entre 1937 y 1938 que aseguraran "el desayuno escolar como parte del desarrollo integral de los niños. ${ }^{20}$

En cuanto al apoyo al aborto, este se sustentó en la necesidad de promover el control de los nacimientos en relación a las condiciones de vida de las obreras. ${ }^{21}$ Y se asoció a la crítica a los hombres-gobernantes que encubrían, guiados por una racionalidad instrumental y masculinista de la política pública, las miserables condiciones de vida en los conventillos al enaltecer el crecimiento y modernización de las ciudades e invisibilizaban los arrabales habitados por obreros que construían estos modernos avances urbanos. Por esta razón, declaraban con una mordacidad admirable para mujeres que no tenían derecho a expresión pública: "como acostumbran a decir estos señores que rigen los destinos de este país con un creciente superávit". ${ }^{22}$ Del mismo modo, calificaron el Estado gobernado por hombres como "Oligárquico y burocrático", "Estado Patrón”, con lo que aludían a las formas conservadoras y latifundistas que consolidaban las desigualdades para las mujeres. Y afirmaron con ironía moralizante que el gobierno de Alessandri no les rendía "homenaje de cortesía” de acuerdo con las costumbres sociales dominantes. Al no recibirlas para escuchar sus reclamos en el pliego presentado para rebaja a los artículos de primera necesidad en 1936, se declaró: "No se les recibió en audiencia ni se les ha contestado su pliego de peticiones. ¡Son demasiadas cosas juntas!". ${ }^{23}$

El cuestionamiento al orden conservador, a sus subordinaciones, desigualdades de género y resistencias en el escenario público a los actos emancipatorios del movimiento, lo expresaron con un tono vehemente teñido de sarcasmo en el uso de las preguntas y las cifras:

20. DIXI, "La Instrucción Obligatoria y el niño proletario”, La Mujer Nueva (Santiago) enero de 1936: 1 .

21. "Necesidad del control de los nacimientos. El problema del aborto y la mujer obrera", La Mujer Nueva (Santiago) febrero de 1936: 1.

22. Adriana Cienfuegos, "Conventillos", La Mujer Nueva (Santiago) enero de 1936: 3.

23. "Las mujeres no fueron recibidas por S.E.", La Mujer Nueva (Santiago) noviembre de 1936: 1. 
¿Qué entienden por orden estos buenos señores o señoras?

¿Será por ventura orden o mejor dicho, buen orden, de que en Chile mueran anualmente 39.383 niños menores de un año, cifra que corresponde a 262 fallecimientos por cada mil niños que nacen? [...] ¿Será orden que en un año mueran de debilidad congénita, es decir, de hambre, de miseria fisiológica heredada 6.787 niños?

[...] ¿Cuál es el orden que permite que hayan 40.000 niños abandonados y que la cuarta parte de la población sea analfabeta?

Si por orden entienden este estado de cosas, si por orden entienden el sojuzgamiento armado de las masas hambrientas, si por orden entienden el rigor policial para impedir el mejoramiento de las condiciones económicas del proletariado, declaramos abiertamente que somos y seremos sus enemigas más encarnizadas.

Ahora, si se considera la palabra orden en su sentido natural y obvio de "colocación de las cosas en el lugar que les corresponden, es decir de que todo ser humano dentro de la sociedad viva como tal y tenga asegurado un mínimo de bienestar, nadie nos aventajará en la defensa del orden.

Queremos “orden” sinónimo de justicia y no "orden” sinónimo de conservatismo. ${ }^{24}$

Resignificaron desde una mirada de género y de justicia social las bases oligárquicas del poder hegemónico: orden, patria y familia.

Cuando luchamos porque cada madre sea protegida estatalmente solo por el hecho de ser madre, que la vida de sus hijos tengan la posibilidad de llegar a término y que una agendadas se les brinde por parte de la sociedad educación, pan, techo y abrigo; cuando luchamos porque el trabajo de la obrera se remunere lo mismo que el de su compañero, que las leyes sociales la protejan a su vez en la maternidad, cuando luchamos porque a la mujer de cualquier clase social se le reconozcan amplios derechos como ciudadana ya sean políticos, civiles o jurídicos, parece que estamos luchando abiertamente por el orden, la familia y por la patria.

Todos los seres normales se apegan y quieren y luchan por lo que les es agradable, por lo que les significa calor y por tanto si nosotras queremos que las mujeres lo crean y amen y luchen por el orden y por la grandeza de la familia y de la patria debemos empezar por proveerles sus beneficios.

La madre trabajadora no puede creer en el orden social en el momento en que no lo siente una continuación ni una superación del orden de la naturaleza.Y así no tampoco consecuentemente en la familia, ni en la patria. ${ }^{25}$

Junto con enfrentarse a la oligarquía, experimentaron también la violencia de los movimientos fascistas. En una reunión en Valparaíso en que el MEMCH acordó solicitar a los candidatos parlamentarios conceder "a las mujeres iguales derechos políticos, civiles y económicos”, ${ }^{26}$ un grupo de nazis las violentó en la calle y fueron defendidas por jóvenes. Las activistas declararon estar conscientes que estos grupos eran sus enemigos y cuestionaron duramente el inserto sobre el evento

24. "El orden verdadero", La Mujer Nueva (Santiago) marzo de 1936: 3.

25. "Orden, Patria, Familia”, La Mujer Nueva (Santiago) agosto de 1936: 3.

26. María Aracil,"Sin extrañeza”, La Mujer Nueva (Santiago) abril de 1937: 2. 
publicado al día siguiente en La Estrella, versión vespertina de El Mercurio, que señalaba: "Desde anoche han conquistado las mujeres la igualdad con los hombres para recibir garrotazos en boches políticos". Ante lo cual denunciaron la "estupidez" que llevaba a suponer que "las mujeres con los ojos en tinta y sobándose los moretones habían alcanzado la igualdad”. María Aracil presentó nuevamente las demandas sociales y políticas del movimiento y calificó así a la prensa local:

Todo lo escrito tenía el aroma inconfundible que anima la conversación del pije siútico de provincia que sintiéndose importante, en la localidad, se sienta en la plaza a comentar a los paseantes [...] Para el vespertino de la prensa seria, el ataque de los nazistas no tiene por lo demás importancia que un hecho de policía. El gacetillero no ve ni valoriza toda la importancia social que tiene el gesto de unos trogloditas atacando a mujeres que luchan por su emancipación dentro de esta sociedad feudal. El gacetillero solo ve la magnífica oportunidad de hacer un párrafo truculento y lo hace con toda esa espontaneidad del anonimato como el que ya se sabe resguardado de miradas ajenas y exhibe dentro de su cuarto toda su miserable humanidad y la rasca y la despulga y la refocila en gesto plebeyo. ${ }^{27}$

El desprecio a la caricatura de "la feminista" que encubría el menosprecio a las mujeres organizadas fue devuelta con calificativos de igual talante para la prensa que las cuestionaba. ${ }^{28}$ Estas acciones se desarrollaron en un contexto político desigual para las mujeres. La lucha por el voto femenino iniciada en los años veinte les había conferido el derecho a participar en las elecciones municipales en 1934 y se encontraba pendiente la consolidación del voto universal (1949). Por ello, estas discusiones y articulaciones entre la política pública (salud, trabajo), las alianzas con los partidos y movimientos, las visiones confrontadas sobre los ideales sociales y hegemónicos sobre la mujer, así como los procesos de organización al interior del propio movimiento, enuncian una perspectiva del republicanismo cívico. ${ }^{29} \mathrm{El}$ cual considerado de manera restringida dio cuenta de una ciudadanía de mujeres organizadas que utilizaba los espacios públicos y los recursos culturales disponibles para ampliar las formas de participación en la democracia representativa.

\section{El campo educativo moderno. El MEMCH y formas de educación popular contra la perpetuación de la desigualdad de las mujeres}

La visión integral de la política condujo al MEMCH a intervenir en educación. El campo educativo moderno en construcción, ${ }^{30}$ resultado de una compleja

27. Aracil, "Sin extrañeza” 2.

28. Honneth.

29. María Rosaria Stabili, "La res-pública de las mujeres”, Historia política de Chile, 1810-2010, t. 1, eds. Iván Jaksic y Juan Luis Ossa (Santiago: Fondo de Cultura Económica / Universidad Adolfo Ibáñez, 2017) 243-270.

30. Thomas S. Popkewitz, "La historia del currículum: la educación en los Estados Unidos a principios del siglo XX, como tesis cultural acerca de lo que el niño es y debe ser", Profesorado. Revista de Currículum y Formación del Profesorado 11.3 (2007): 1-13. 
combinación de procesos de regulación dirigidos por el Estado sobre movimientos de transformación y contención de los procesos sociales, ${ }^{31}$ fue integrando, no sin contradicciones, referentes científicos y filosóficos con derechos sociales, la cultura del trabajo y diversas propuestas de los agentes sociales en torno a temáticas como la educación pública, el bienestar, la protección, el progreso económico, la igualdad de oportunidades y la democracia. Para armonizar las necesidades sociales y las relaciones entre individuo, sociedad y Estado, la noción liberal de ciudadano actuaría como dispositivo vinculante con la democracia y los propósitos educativos serían asumidos por la pedagogía experimental o escuela nueva, propuesta educativa democrática liberal de las sociedades capitalistas industriales. ${ }^{32}$

La participación de los movimientos sociales en el campo educativo y su propia complejidad al integrar demandas sociales y políticas con formas de regulación social contribuyeron a profundizar las contradicciones del discurso universalista, evolutivo y civilizatorio del ideario liberal de la instrucción pública latinoamericana. ${ }^{33}$ Ideario que, por su parte, consolidaba las desigualdades y subordinación de las mujeres ${ }^{34}$ y a la vez apoyaba la difusión del conocimiento a toda la sociedad a través de la educación con lo que tensionaba las tradiciones morales y culturales ancladas en la Iglesia católica, las cuales negaban y restringían el ingreso de las mujeres a la educación secundaria. Además, enunció la contradicción entre el reconocimiento del acceso femenino a la educación superior y la negación de su derecho al sufragio. ${ }^{35}$ Estas disociaciones discursivas se expresaron a través de ajustes formativos y curriculares en el propio sistema educativo que agudizaron las desigualdades de género al separar educación teórica de la práctica. La primera correspondía a los hombres, vinculada al conocimiento científico, y la segunda a las mujeres, asociadas a conocimientos prácticos para labores subvaloradas y a la vida doméstica. Se acompañaba de la promoción de una educación moral para todo el sistema educativo y los espacios de sociabilidad con la idea de "mujeres madres y esposas", es decir, reproductoras del orden social oligárquico. El MEMCH desarrollaría formas combinadas de educación popular entre las mujeres trabajadoras orientadas desde la justicia y la igualdad, algunas de las cuales pasamos a desarrollar.

31. María Angélica Illanes, Cuerpo y sangre de la política. La construcción histórica de las Visitadoras Sociales (1887-1940) (Santiago de Chile: LOM Ediciones, 2006); María Angélica Illanes, "En el nombre del pueblo, del Estado y de la ciencia, (...)”. Historia social de la salud pública en Chile 1880 / 1973. (Hacia una historia social del siglo XX) (Santiago: Ministerio de Salud, 2010).

32. Martha Cecilia Herrera Cortés, Modernización y Escuela Nueva en Colombia, 1914-1951 (Bogotá: Plaza \& Janés Editores / Universidad Pedagógica Nacional, 1999); Popkewitz.

33. Marcela Gómez Sollano y Adriana Puiggrós, "Estudio preliminar a la edición argentina: la educación popular en América Latina", Fuentes sobre alternativas pedagógicas populares en América Latina (Buenos Aires: Editorial de la Facultad de Filosofia y Letras, Universidad de Buenos Aires, 2019) 21-36.

34. María Isabel Orellana Rivera, El lugar de la ciencia en la educación de las mujeres, t. 1 (Santiago: Ediciones Museo de la Educación Gabriela Mistral, 2018).

35. Ernesto Turenne, "Profesiones científicas para la mujer", Revista Chilena (Santiago) 1877:352-427. 


\section{La libertad individual y el sistema educativo: dispositivos de desigual- dad en la educación de las mujeres}

El avance del Estado Docente en la consolidación de los postulados ilustrados y liberales entre 1870 y 1950 enfrentó el rechazo de las élites conservadoras al desarrollo de la educación secundaria gratuita estatal para las mujeres. ${ }^{36}$ La defensa de la educación privada secundaria para mujeres se basó en la conservación de los privilegios asociativos de las élites por el temor a la pérdida del control formativo y a los cambios del orden social vigente que estos procesos pudieran generar. Desde la adhesión corporativa a la defensa de la libertad de enseñanza ante el avance del Estado en el periodo, defendieron el poder de los padres sobre la educación de sus hijos como un derecho divino y cuestionaron la potencial dominación ideológica del Estado al crear liceos fiscales. Con una lógica más economicista, señalaron la "injusta competencia" que el Estado llevaría a cabo (con el dinero de todos) contra el sector privado y cuestionaron la capacidad de los profesionales de la educación para evaluar a sus hijos. ${ }^{37}$ Del mismo modo, las políticas educativas para la expansión de la educación secundaria de mujeres fueron débiles y de lento desarrollo dado que no contemplaron soportes institucionales consolidados (las partidas para la asignación de recursos no fueron permanentes) y su relación con los diversos territorios ${ }^{38}$ ni integraron demandas de cobertura e infraestructura ni consideraron la asignación de personal con capacidades existentes y salarios igualitarios. ${ }^{39}$

Así, hacia 1910 la tasa nominal de cobertura (según matriculados) de la enseñanza elemental era del orden de un 37\%. En el nivel secundario, en el mismo periodo, en los liceos había 11,719 alumnos matriculados; 8,739 en liceos fiscales de los cuales un 10\% eran mujeres y 2,980 en liceos particulares, el 30\% de ellos mujeres. El liceo tenía escuelas preparatorias (primarias propias) a las que llegaban a formarse los alumnos más talentosos de los sectores medios y de clase alta. ${ }^{40}$ Esta situación, unido al currículo organizado en una modalidad dual entre primaria y secundaria, consolidó un sistema educativo que territorialmente ${ }^{41}$ reproducía las relaciones centro periferia y las desigualdades y segregaciones de clase, género e intragénero en el acceso a la educación. Del mismo modo, conservando el mismo orden del sistema educativo, la Ley de Instrucción Primaria Obligatoria (1920), al

36. Orellana Rivera.

37. Orellana Rivera.

38. Véase Sebastián Donoso Díaz, El derecho a educación en Chile. Nueva ciudadanía tras el ocaso neoliberal (Santiago: Bravo y Allende Editores, 2013).

39. Orellana Rivera.

40. José Joaquín Brunner, "Los debates de la república educacional: 1910 y 2010”, septiembre de 2007. https://www.academia.edu/16199627/Los_debates_de_la_Republica_Educacional_1910_y_2010 (03/02/2020).

41. Leonora Reyes J., "Escuela pública y sistema escolar: transformaciones históricas y proyecciones”, Docencia 44 (2011): 48-63; Carlos Ruiz Schneider, De la República al mercado. Ideas educacionales y política en Chile (Santiago: LOM Ediciones, 2010). 
establecer la obligatoriedad de la educación hasta la edad de 12 años, excluía a las mujeres obreras del acceso a la educación. ${ }^{42}$

El periodo 1935-1941 conforma un ciclo de tránsito entre este orden y las nuevas propuestas socio educativas (escuela nueva) y políticas del estado benefactor-desarrollista. Estas últimas serían abruptamente discontinuadas por el desplazamiento de las reformas educativas a procesos de planificación sistemática como la antesala no esperada, al finalizar la década de 1940, de modalidades globalizadas instaladas desde la Guerra Fría por la política norteamericana en el continente. ${ }^{43}$ En este ciclo la participación de los movimientos sociales en el campo educativo desarrollaría una lectura contra hegemónica del principio de libertad de enseñanza, lo que desplazó su uso desde una orientación liberal hacia la defensa de la igualdad de derechos. Este recorrido es visible en el caso del MEMCH en el periodo 1935-1941 en las discusiones sobre los derechos de las mujeres como sujetos políticos y en las prácticas de educación popular que abordan sus problemas propios a escala nacional y local territorial, los que habían sido negados e invisibilizados por la política pública. Estas formas de educación popular se caracterizaron por su base experiencial y su relación con un entramado histórico específico de lucha ${ }^{44}$ por el reconocimiento de sus derechos como sujeto político y por la demanda de consolidación identitaria. ${ }^{45}$ Dichas orientaciones se inscriben en procesos educativos y políticos complejos de largo alcance que cruzan a los movimientos sociales en los cuales, simultáneamente, requieren fortalecerse a sí mismos, deconstruir la naturalización del orden dominante, democratizar el ejercicio del poder, aprender de sus prácticas para superar falsos dilemas y socializar sus contenidos propios en un campo socio cultural más amplio, y a la vez expandir y consolidar su incidencia en la transformación del Estado. ${ }^{46}$

\section{El MEMCH y una educación popular militante para el reconocimiento de las mujeres como sujeto político y para la emancipación}

Para que la visión integral de la política se consolidara y transformara la sociedad, desarrollaron estrategias de educación popular. Estas se centraron en la fundación de escuelas primarias que tenían como finalidad alfabetizar y preparar para el trabajo a las mujeres obreras y que desplegaban su actividad mediante el desarrollo de intervenciones educativas ancladas en organizaciones locales que promovieron

42. Braulio Carimán Linares, "El 'problema educacional' entre 1920-1937: una historia de reformas y limitaciones”, Universum 27.2 (2012): 31-44; Ruiz Schneider; Donoso Díaz.

43. Iván Núñez P., La producción de conocimiento acerca de la educación escolar chilena (1907-1957) (Santiago: Centro de Perfeccionamiento, Experimentación e Investigaciones Pedagógicas, 2002).

44. Gómez Sollano y Puiggrós.

45. Alonso Torres Carrillo, "Prácticas educativas en movimientos sociales de América Latina", Folios 46 (2017): 3-14. DOI: 10.17227/01234870.46folios3.14.

46. Mario Garcés, "Los movimientos sociales en la transición: a 30 años del plebiscito de 1988”, Las largas sombras de la dictadura: a 30 años del plebiscito, ed. Julio Pinto (Santiago: LOM Ediciones, 2019) 91-136. 
formas de educación sobre salud (cuestión social para mujeres) y asesorías jurídicas para el conocimiento de las leyes laborales y del matrimonio (vida privada). Estas prácticas sustentadas en la igualdad de derechos sociales y en el reconocimiento de las mujeres como sujetos políticos, con derechos civiles, se contrapusieron a la visión hegemónica. ${ }^{47}$ Fueron lideradas por mujeres, enfatizaron "lo propio", intervinieron los territorios relacionándose con diversos agentes sociales y articularon conocimiento y cultura política en un contexto de crisis del Estado decimonónico que se encontraba en tránsito a uno desarrollista benefactor, proceso marcado por las resistencias conservadoras y por la emergencia de los fascismos y formas militarizadas en la vida social.

Las prácticas de educación desarrolladas por el MEMCH entre 1935 y 1941 muestran una relación entre su expansión y el aumento de la discusión política y la polarización social. Caracterizan a estas formas de educación popular su orientación hacia la acción, su ejercicio autónomo y colaborativo con otros movimientos, asumir la instrucción como una transmisión distributiva del conocimiento oficial para igualar los accesos educativos y sociales de las mujeres y su despliegue territorial a lo largo del país. El movimiento consideraba que el trabajo y la instrucción conducirían a las mujeres a la emancipación. En un tono esperanzador propio de los principios ilustrados que lo animaban y que pretendía convocar a un colectivo, afirmaba:

El vasto desarrollo logrado por la técnica industrial ha enseñado un nuevo camino a la mujer trabajadora. La universidad ha abierto las puertas a la mujer estudiosa. El trabajo y la educación son los factores que independizan a la mujer económica e intelectualmente. La independización integral ha surgido como la resultante de estas fuerzas adquiridas. Hay que reconocer lealmente que son derechos conquistados palmo a palmo y después de rendir pruebas fehacientes de capacitación. ${ }^{48}$

El desarrollo de redes colaborativas en los territorios para el trabajo educativo con crecientes masas de mujeres y niños analfabetos invisibilizados por el Estado se articuló con diversos actores. Por ejemplo, con la Unión de Profesores implementaron sus propias escuelas en 1936. La iniciativa hizo crecer la demanda de escuelas para las trabajadoras y para sus hijos. Una carta de una obrera de lavaderos de oro de Algarrobo en 1937 daría cuenta de la educación como un valor social y de la importancia para sus hijos:

En diversas ocasiones hemos pedido al Gobierno un campamento y una escuela para los cerca de 50 niños que hay sin saber leer. Otro de nuestros pedidos sin ser escuchados. El campamento lo pedimos para cobijar a nuestros hijos del frio y la lluvia que ya se avecina. Hasta ahora vivimos en

47. Gómez Sollano y Puiggrós.

48. María Antonieta Garafulic, "Proyecciones del movimiento emancipacionista femenino", La Mujer Nueva (Santiago) noviembre de 1935: 2. 
ramadas que han hecho nuestros maridos. Hay que considerar que nosotras trabajamos aquí como quien más sacando el oro que por cierto no es para nuestras necesidades. El pasa por nuestras manos mientras nos morimos de hambre y frio. ${ }^{49}$

La creación de escuelas debió enfrentar momentos complejos del contexto político de 1937 en el cual a nivel local se reproducían los enfrentamientos entre comunistas y fascistas. Así, en el periódico El Esfuerzo, identificado como representante de la clase obrera, se acusaba a una escuela que funcionaba en el subcomité del MEMCH en Quinta Normal de ser "clandestina”, un "centro comunista”, y de contravenir la norma de enseñar sin tener el título correspondiente. Ante lo cual declararon con ironía: "Todo lo anterior es por cierto un atado de incongruencias y falsedades, puesto que en "la escuela clandestina" se puede inscribir quien desee aprender a leer y a escribir, sin mayores antecedentes.Y a pesar de que cualquiera puede enseñar en locales particulares sin título alguno, todas las profesoras que tenemos a nuestro servicio son maestras o profesionales". ${ }^{50}$

Del mismo modo defendieron su autonomía respecto de los partidos políticos diferenciándose de sus lógicas de cálculo; afirmaban: "Nuestra organización no es política ni militante pero a diferencia de aquellos que ocultan siempre su relaciones con partidos o elementos políticos, de mayoría gobiernistas tras frases de prescindencia política, dejamos a nuestra gente en libertad de acción para que militen donde quieran" ${ }^{51}$ Asimismo, cuestionaron la falta de consistencia política del diario al burlarse de la ignorancia de la clase obrera que decía representar y lo conminaron a involucrarse en la educación de su clase y con ironía fina defendieron el derecho a educarse:

No sería mejor si a los directores de "El Esfuerzo", les interesara verdaderamente la cultura de su clase que emplearan su periódico en algo que realmente valiera la pena $[\ldots]$ ¿Cómo es posible que teniendo el pueblo chileno todo por aprender, se haga un semanario para él en que se encuentran solo versos malos y galimatías. Después de leer "El Esfuerzo" (Con mucho esfuerzo) quedamos convencidas de la necesidad de abrir muchas pero muchas "escuelas clandestinas" y una especial para sus directores. ${ }^{52}$

En la misma línea, la creación en 1936 del Instituto de Cultura Obrera, que utilizó inicialmente la sede del MEMCH, se orientó a impartir educación elemental a mujeres adultas obreras y, en general, para instruirse en las primeras letras. "El Memch ha cedido galantemente su local a este Instituto que creemos va a satisfacer una sentida necesidad para las mujeres de escasos recursos"..${ }^{53}$ La propuesta

49. "En los lavanderos de oro de Algarrobo", La Mujer Nueva (Santiago) marzo de 1937: 6.

50. "Denuncia escuela clandestina", La Mujer Nueva (Santiago) marzo de 1937: 6.

51. "Denuncia escuela" 6.

52. "Denuncia escuela" 6.

53. "Instituto de Cultura Obrera", La Mujer Nueva (Santiago) enero de 1936: 4. 
fue ampliándose con modalidades flexibles para instalarse en los mismos lugares de trabajo y con el ajuste de sus conocimientos a las realidades de las mujeres trabajadoras. Así, en el mismo año se destacaba el éxito de esta modalidad educativa: "Con gran éxito se ha abierto la matrícula de este Instituto, en los diferentes sitios de trabajo. Desde luego, funcionarán algunas clases para analfabetas y semialfabetas en el local del Sindicato Mc-Kay ubicado en Chacabuco 54 y en el Sindicato de la Aguja en Santo Domingo 1274. También se dictarán cursos de legislación obrera y otros de conocimientos generales de primer grado", ${ }^{54}$

Esta estrategia de educación popular como instrucción se diferenciaría de la estrategia de creación de escuelas técnicas femeninas (desde 1887) implementadas por asociaciones corporativas oligárquicas, las cuales se habían orientado a la formación de mujeres para el trabajo remunerado en la industria local y su disciplina moral hacia la reproducción del orden social. El MEMCH desde una particular lectura del positivismo y funcionalismo de la época entendía su implementación dentro de un proyecto social evolutivo en el cual las mujeres eran el eje principal en torno al cual giraba el régimen económico, "al modificarse las condiciones de vida de las mujeres, se modificará sustancialmente las condiciones de la sociedad ya que ella es el principal eje alrededor del cual gira la sociedad misma" ${ }^{55}$ Ello suponía dar "soluciones científicas a los problemas sociales" para asegurar el progreso de la sociedad y abordar los problemas específicos de las mujeres que se han señalado.

El Movimiento mantendría esta estrategia de forma constante. Enfatizaba en 1939:

La falta de conocimientos elementales en la mujer del pueblo es la que ha permitido su permanencia en el triste estado que le es característico. A la mujer se le ha dicho que debe soportarlo todo y así ella lo ha creído. Se le ha convencido que su inferioridad no le permite reclamar mejores derechos.Y, así ella lo ha aceptado. Hay que ir rápida y certeramente a la alfabetización de las masas y a la inculcación de principios de cultura general. Es preciso ligar a la mujer con su país, hacerla sentir que sus problemas son recíprocos y, que ella no es una paria dentro de la sociedad. El Memch tiene la intención de habilitar las escuelas o cualquier otro sitio, adecuado para desarrollar desde ellos una labor en ese sentido, labor que debe considerarse según el material humano naturalmente. A una mujer que trabaja duramente todo el día no se le puede exigir que vaya a estudiar programas más o menos áridos. La cultura debe llegar a ella de manera muy sensible y agradable. Hay que encontrar el tono y eso es lo importante. ${ }^{56}$

Los comités también desarrollaron articulaciones con otras asociaciones para promover formas de educación para niños, además, debieron enfrentar conflictos territoriales, ya que tanto las escuelas populares como sus formas educativas desafiaban el imaginario social segregador oligárquico. La mirada transversal de

54. "Actividades del movimiento Pro-emancipación de las mujeres de Chile", La Mujer Nueva (Santiago) marzo de 1936: 4.

55. Garafulic, "Proyecciones" 2.

56. "La cultura para la mujer es el clamor del Memch!”, La Mujer Nueva (Santiago) julio de 1939: 4. 
la política sería evidente en el caso de la instalación de una colonia de verano para hijos de obreros en las inmediaciones de una escuela en Reñaca. ${ }^{57}$ Para ello el MEMCH se había aliado con la Junta de Beneficencia Escolar local en 1936. Elvira Santa Cruz, encargada de su implementación, respondió a una carta de un representante de los vecinos que la rechazaba en la que se argüían razones técnicas (costos, traslados de médicos, alimentos, etcétera), aunque escondía prejuicios clasistas. Reafirmando la dimensión que alcanzaba la lucha de clases y la defensa de la igualdad promovida por las mujeres en el territorio señaló: "Se discute si existe o no, la lucha de clases en el país, yo digo que existe. Comienza esta lucha con el niño desvalido". ${ }^{58}$ Luego argumentó los procedimientos que utilizarían para implementar las actividades:

Advierto que este local no está destinado a niños vagos o mendigos sino a escolares desnutridos que requieren de un cambio de clima. Antes de conducirles a las Colonias los niños son sometidos a una encuesta social a un prolijo examen médico y dental a fin de eliminar a todo el que tenga una enfermedad contagiosa. La atención que prestamos al hijo del obrero es la misma que presta el gran señor a los suyos. Por lo tanto tal como él evita el contacto epidémico para su hijo, nosotras que también somos responsables de las vidas que se nos confian procuramos resguardar al colonito de todo contagio peligroso. ${ }^{59}$

Y agregó irónicamente contra la oligarquía local:

Pues bien, y a pesar de haber refutado muchas veces la argumentación egoísta de los poseedores de la riqueza, se ha protestado en corrillos de pasillos y aun en la prensa contra la construcción de la Colonia Escolar de Reñaca, dando razones más incongruentes e inauditas. Dicho edificio, afeara el balneario, los menesterosos traerán plagas infecciosas, los hijos de la miseria invadirán la playa por ese motivo los niñitos bien no podrán frecuentarla... Deberían irse a una playa lejana, ¿Por qué no a la punta del cerro? ¿No les basta con ser dueños de la tierra? ¿Pretenden también adueñarse del cielo y de la tierra? ${ }^{60}$

En la estrategia desplegada territorialmente se observan referentes higienistas en torno al control y educación de los niños, los cuales fueron orientados desde el principio de la igualdad, entendida como opuesto a los privilegios de la clase dominante. Asimismo, se vincularon estos principios con el imaginario de comunidad cristiana: ${ }^{61}$

57. Balneario del litoral central del país, donde residía la oligarquía.

58. Elvira Santa Cruz, "La creatura Humana”, La Mujer Nueva (Santiago) diciembre de 1936: 3.

59. Santa Cruz, "La creatura" 3.

60. Santa Cruz, "La creatura" 3.

61. Los proyectos educativos alternativos en América Latina se han conformado a partir de elementos de comunidades imaginadas basadas en fundamentos del socialismo utópico europeo y en el cristianismo, los cuales son revisitados en distintos contextos históricos. Gómez Sollano y Puiggrós. 
Yo estoy habituada desde hace veinte años atrás a convivir con los niños de la clase obrera que los he visto llegar a nuestras Colonias paliduchos, desfallecientes, con le cuerpecito sucio, he hecho el siguiente descubrimiento, de que estos chicos después de dos semanas de buena alimentación de baño e higiene, son tan limpios, tan inteligentes y tan semejantes a los niños ricos... Cuando los padres de familia acuden a visitar a los niños en días feriados, el ambiente igualitario fraternal se acentúa mucho más... la mesa del comedor se alarga, los panes se multiplican y todos juntos, niños, maestras, obreros renuevan el milagro de esos lugares cristianos. ${ }^{62}$

Junto con estas estrategias y de modo combinado de acuerdo con los contextos políticos y las necesidades territoriales desarrollaron "intervenciones educativas de expertos/as". En estas se transfería conocimiento científico aplicado a la vida y a las necesidades de las mujeres en sus entornos sociales. Esto lo realizaban los comités de barrio que implementaban consultorios de salud en los que se dictaban charlas, se prestaban atenciones médicas, acciones preventivas e instrucciones para el uso de anticonceptivos, sobre el embarazo y el cuidado de los niños. También socializaron conocimientos jurídicos sobre leyes laborales y el matrimonio.

A través de estas prácticas educativas gratuitas, o con un pago mínimo, intervenían escenarios de la vida cotidiana que habían sido hegemonizados por hombres y que establecían condiciones sociales y culturales desiguales para las mujeres. Su despliegue se articuló en alianza con organizaciones de trabajadores, vecinales y asociaciones en territorios de poblaciones obreras. Tal es el caso de la conformación de un comité en Mapocho en que la secretaria del MEMCH dio a conocer el programa de trabajo y "Una delegada de la Federación obrera de Chile (FOCH), usó la palabra para expresar su apoyo de la organización que representaba al programa del Memch y explicó a los asistentes que sólo una campaña constante de todas las mujeres podría darnos el bienestar que necesitamos". ${ }^{63}$ Sobre una de las intervenciones educativas en salud en 1935 en la población San Martin se declaraba: "Se ha instalado en esta población un consultorio médico que va mejorando cada día y que ha sido recibido con gran entusiasmo por todos los pobladores. El secretariado de este comité trabaja activamente para llevar fondos para ampliar los servicios del consultorio. Periódicamente se efectúan charlas para elevar el nivel cultural de la mujer en temas que los mismos pobladores indican". ${ }^{64} \mathrm{El}$ movimiento comprometió en 1936 tanto a profesionales como a pobladoras para ampliar y continuar el funcionamiento de los consultorios en la misma población, lo mismo con cursos de legislación social y obrera en los cuales se abordaban temas sobre el contrato matrimonial, la patria potestad y el derecho a usufructo y administración de los bienes de sus hijos.

La Mujer Nueva aportaba a esta práctica como estrategia autoeducativa que difundía estos temas periódicamente y con intensidad en contextos de preparación

62. Gómez Sollano y Puiggrós.

63. "De nuestras actividades", La Mujer Nueva (Santiago) diciembre de 1935: 4.

64. "De nuestras actividades" 4. 
de los congresos nacionales. Como el de 1937, que estuvo orientado a la unidad del movimiento y cuyo foco radicó en la mujer trabajadora y el niño con la finalidad de promover las reformas en leyes de maternidad y trabajo. ${ }^{65}$ El Congreso de 1940, centrado en la incidencia del fascismo en la vida de las mujeres y en el contexto local, en su afectación a la igualdad (desigualdad laboral y política) y a la justicia. ${ }^{66}$ En este último Congreso se discutiría la historia de la educación de la mujer, tema que se presentó mediante una conferencia que abrió el debate.

A pesar de no tener el derecho a voto, el MEMCH apoyó la candidatura de Pedro Aguirre Cerda en 1938 para lo que desplegó dos estrategias: la realización de declaraciones formales de apoyo tendientes a la profundización de la democracia y la solución de los problemas que aquejaban al pueblo, ${ }^{67}$ mediante la reversión de las prácticas socioculturales oligárquicas que asignaban a las mujeres funciones reproductoras del orden. En este caso, llamaban a sus "compañeras" a inducir a sus maridos e hijos a votar por el Frente Popular. Sin embargo, este apoyo no estuvo exento de conflictos con los partidos que no aceptaban su participación en las campañas y en la distribución de funciones políticas. Cuestionaban el número de inscripción de mujeres para participar en las elecciones municipales en 1937 y consideraban la victoria de los sectores conservadores en las elecciones precedentes (1934), por lo que llamaron a las mujeres a inscribirse e interpelaron a los hombres para reconocer sus derechos políticos:

Han pasado casi cuatro años y no hemos dado mayores pruebas de haber aprovechado la elección y la experiencia. Reina la misma indiferencia para hacer trabajos de preparación e interés femeninos. La tarde del día que se efectuaron las elecciones municipales, los hombres se congregan a quejase, que el voto femenino hubiera causado tal desastre. Y ¿Qué han hecho ustedes ahora durante 4 años por evitarlo, nos preguntamos? El Partido Radical y el Partido Socialista han realizado grandes congresos en los que se han tratado extensamente todos los temas, menos el del trabajo femenino. El partido Comunista aún no ha efectuado su Congreso pero podemos

65. "Cursos", La Mujer Nueva (Santiago) abril de 1937: 8; "Patria Potestad", La Mujer Nueva (Santiago) julio de 1937: 2.

66. El Congreso destacó como una gran instancia de autoeducación en el que se mostraba la organización de temas a preparar y sus derivaciones para la discusión desde la vida de las participantes, tales como: aplicaciones prácticas de los derechos civiles y políticos de las mujeres chilenas, movimiento feminista mundial, evolución social y política de Chile, la legislación social y de la mujer. Además, discusiones a través de ejemplos con temas sobre igualdad y protección de la mujer respecto del hombre en el trabajo, conceptos de asistencia social y caridad, paz y democracia, entre otros. Cada uno de los temas desarrollados iba con su relatora responsable y era acompañado con discusiones sobre organización y relaciones con otros movimientos. "Congreso Nacional del Movimiento Pro-Emancipación de las Mujeres de Chile", La Mujer Nueva (Santiago) febrero de 1941:1-6; "Cursos obligatorios para las delegadas al $2^{\circ}$ Congreso del MEMCH", La Mujer Nueva (Santiago) septiembre de 1940: 8; "Nuestro Segundo Congreso", La Mujer Nueva (Santiago) noviembre de 1940: 3.

67. Aída Yávar, "Opina la presidenta del comité femenino", La Mujer Nueva (Santiago) octubre de 1938: 2. 
opinar que nos parece al bien, superior al de los otros partidos. Pero sobre todo en el Partido Radical es donde observamos la mayor desproporción entre sus posibilidades y los hechos en lo que a este problema se refiere. ${ }^{6}$

Una vez en la presidencia de Aguirre Cerda (1938-1944), quien se había comprometido reconocer el derecho a voto de las mujeres, el movimiento se dispuso a colaborar integralmente con las nuevas políticas. Su gobierno fue calificado como el inicio de "Una nueva era para las mujeres chilenas" en que "se formará la mujer que formará Chile", ${ }^{69}$ pero ya hacia 1941 se constataba que su situación no había cambiado.

En este contexto observamos la participación de integrantes del MEMCH en las políticas educativas implementadas por el gobierno, así como la continuidad del fortalecimiento de la educación como instrucción en escuelas nocturnas para mujeres. A ello se agregaría la convergencia entre "educación y cultura" que operaría como sustento de formas de educación dirigidas a madres e hijos en los barrios, en los llamados Centros de Cultura Popular (1938-1939).

La participación de Graciela Mandujano como subdirectora en el Instituto de Información Campesina (1939) fue destacada en periódico, en cuyas páginas declaró sobre los propósitos:

No se imagina el interés que ha despertado la creación de este organismo así como también nuestra primera publicación. A diario recibimos una enorme correspondencia de las más diversas personas y lugares en las que nos dan sobre todo, consejos. Estos nos producen es constatar que nuestra obra ha nacido viva. Queremos por sobre todo llegar a los campesinos, despertar su interés por la cultura y el mejor aprovechamiento de los medios de vida. ${ }^{70}$

Sin embargo, el Instituto dirigido por el latifundista Horacio Serrano estuvo destinado a modernizar la vida y la producción campesina junto con una alfabetización e instrucción de masas (hombres y mujeres) basada en una imagen de "huaso" (subordinado) creada por las élites, la cual fortalecía el paternalismo agrario y bloqueaba la participación de las campesinas y los campesinos en las organizaciones sindicales que venía en alza desde $1933 .^{71}$ Si bien el MEMCH venía desarrollando una perspectiva de transmisión de conocimiento y la instrucción con la finalidad de emancipar y politizar a las mujeres, la apropiación de estos componentes por la política pública y las élites y su aplicación a otros sectores

68. "Los partidos frentistas deben vencer su indiferencia hacia los problemas de la mujer", La Mujer Nueva (Santiago) julio de 1937: 8.

69. “¡Una nueva era para la mujer chilena! 1938-1944. ¡Años en que se formará la mujer que formará a Chile!", La Mujer Nueva (Santiago) diciembre de 1938: 1.

70. "Entrevistamos a Graciela Mandujano”, La Mujer Nueva (Santiago) julio de 1939: 6.

71. Nicolás Acevedo Arriaza, "El libro del huaso chileno. El Instituto de Información Campesina y las movilizaciones campesinas (1939-1943)", Revista de Historia Social y de las Mentalidades 21.2 (2017): 117-141. 
sociales muestra los dilemas y contradicciones de reproducción versus transformación en que se debate la participación de integrantes de los movimientos sociales en las políticas educativas.

La valoración de la educación de las trabajadoras se consideró trascendental para la vida de las mujeres, lo que se podía observar en las formas de trabajo educativo ajustadas a las necesidades de las participantes y en el carácter moralizante que se pretendía transmitir de la experiencia. También se distinguen aspectos no abordados por esta educación tales como la subordinación cultural y los roles de género y hasta ciertas connotaciones elitistas subyacentes en el movimiento:

En un anochecer lluvioso y frio llegue al local de la Sociedad Dávila ubicada en la calle San Francisco, 668 donde funciona los días Lunes, Martes Miércoles y Jueves de 6 a 7 pm una escuela para adultas bajo el auspicio del Comité Pro Cultura Popular. Llegué con el ánimo deprimido quizás por los afanes de la lucha diaria y con la disposición contraria a la impresión que ahí recibiría. En una amplia sala con regular asistencia, mujeres de distintas edades estaban ahí con un interés de digno encomio sentadas en sus bancos, deletreando algunas bajo la inteligente dirección de abnegadas profesoras, las letras de nuestro alfabeto, otras se entregaban con verdadero deleite a descifrar el intrincado laberinto de los números y otras, muy previsoras aprendían con verdadero interés el difícil arte del corte y de la confección [...] Me acerque a una de ellas de aspecto inteligente y ordenada que había llegado allí, tres meses atrás sin saber leer y escribir, según me dijeron, es una de las alumnas de mayor valer con que cuenta la escuela. Me confesó que para poder venir a clases debe dejar sus ollas puestas en el fuego pues al terminar sus estudios es ya la hora en que su esposo regresa al hogar y debe encontrar por tanto la comida lista. Charle luego dos palabras con otra de las alumnas cuyo caso caracteriza hasta donde llega a veces la constancia de la mujer. Entró al curso cuando ya iba a ser madre. Se notó su ausencia [...] pues bien al cabo de unas cuantas semanas concurrió nuevamente, pues bien esta vez no llego sola: en sus brazos traía jubilosa el fruto de sus entrañas [...] Nuestras compañeras memchistas deben considerar esta maravillosa obra de colaboración social a cuya creación tanto han contribuido. Algo así como nuestra obra maestra. Ella significa llevar a la práctica el principio el mismo de la doctrina que sustentamos: mostrar a las mujeres proletarias la ceguera en que se encuentra sumida y ayudarla a su liberación. ${ }^{72}$

\section{Reflexiones finales}

Las estrategias de educación popular formaron parte de una visión integral de la política del MEMCH para consolidar sus propósitos de reconocimiento de derechos y autonomía de las mujeres al despuntar la década de 1930. Estas estrategias se caracterizaron por ajustar sus formas y contenidos a sus necesidades, desarrollar articulaciones con organizaciones ya existentes y sustentarse en una concepción

72. Antonieta Alberti de Leiton, "Una visita a la Escuela de Adultas", La Mujer Nueva (Santiago) septiembre de 1940: 4. 
“de liberación igualadora" y en la defensa de sus derechos civiles y políticos aún no reconocidos por la sociedad y el Estado. Para ello, a través de estas prácticas educativas intervinieron las desigualdades del sistema educativo, reorientaron la libertad de enseñanza desde la igualdad y promovieron la educación popular en los territorios en ámbitos específicos de expresión de la desigualdad, lo que revirtió la subordinación de las mujeres. Salud, aborto, derechos laborales, matrimonio y alfabetización serían sus focos primordiales. Estas formas de educación popular históricamente situadas combinaron elementos pedagógicos ilustrados con la transferencia de conocimiento con enfoque diferenciado a las mujeres (trabajadoras, dueñas de casa, campesinas, etc.), la promoción de su inserción educativa y productiva y, además, la apertura a sus contextos reales de desarrollo. Conforman un conjunto de acciones fundadas en la igualdad de derechos, la autonomía de las mujeres, el feminismo y sus experiencias que estaban orientadas a transformar las bases políticas y educativas vigentes desde la perspectiva de los movimientos sociales.

\section{Fuentes}

\section{Periódicos y revistas}

La Mujer Nueva (Santiago) 1935-1941.

Revista Chilena (Santiago) 1877.

\section{Bibliografía}

Acevedo Arriaza, Nicolás. "El libro del huaso chileno. El Instituto de Información Campesina y las movilizaciones campesinas (1939-1943)". Revista de Historia Social y de las Mentalidades 21.2 (2017): 117-141.

Antezana-Pernet, Corinne. El MEMCH hizo historia. Santiago de Chile: Imprenta SEIT, 1997.

Brunner, José Joaquín. "Los debates de la república educacional: 1910 y 2010”, septiembre de 2007. https://www.academia.edu/16199627/Los_debates_de_la_Republica_Educacional_1910_y_2010 (03/02/2020).

Carimán Linares, Braulio. “El ‘problema educacional’ entre 1920-1937: una historia de reformas y limitaciones". Universum 27.2 (2012): 31-44.

Donoso Díaz, Sebastián. El derecho a educación en Chile. Nueva ciudadanía tras el ocaso neoliberal. Santiago: Bravo y Allende Editores, 2013.

Garcés, Mario. El movimiento obrero y el Frente Popular (1936-1939). Santiago: LOM Ediciones, 2018.

. "Los movimientos sociales en la transición: a 30 años del plebiscito de 1988”. Las largas sombras de la dictadura: a 30 años del plebiscito. Ed. Julio Pinto Vallejos. Santiago: LOM Ediciones, 2019.

Gómez Sollano, Marcela y Adriana Puiggrós. "Estudio preliminar a la edición 
argentina: la educación popular en América Latina”. Fuentes sobre alternativas pedagógicas populares en América Latina. Buenos Aires: Editorial de la Facultad de Filosofía y Letras, Universidad de Buenos Aires, 2019. Henríquez Vásquez, Rodrigo. En "estado sólido". Políticas y politización en la construcción estatal. Chile, 1920-1950. Santiago: Ediciones Pontificia Universidad Católica de Chile, 2014.

Herrera Cortés, Martha Cecilia. Modernización y Escuela Nueva en Colombia, 19141951. Bogotá: Plaza \& Janés Editores / Universidad Pedagógica Nacional, 1999.

Honneth, Axel. Reconocimiento y menosprecio. Sobre la fundamentación normativa de una teoría social. Madrid: Katz Editores / Centro de Cultura Contemporánea de Barcelona, 2010.

Illanes, María Angélica. “Ausente, señorita”. El niño chileno, la escuela para pobres y el auxilio 1890-1990 (hacia una historia social del siglo XX en Chile). Santiago: Junta Nacional de Auxilio Escolar y Becas, 1991.

. Cuerpo y sangre de la política. La construcción histórica de las Visitadoras Sociales (1887-1940). Santiago de Chile: LOM Ediciones, 2006.

. "En el nombre del pueblo, del Estado y de la ciencia, (...)". Historia social de la salud pública en Chile 1880 / 1973. (Hacia una historia social del siglo XX). Santiago: Ministerio de Salud, 2010.

Lobato, Mirta Zaida. La prensa obrera. Buenos Aires y Montevideo, 1890-1958. Buenos Aires: Edhasa, 2009.

Montero, Claudia. Y también hicieron periódicos. Cien años de prensa de mujeres en Chile 1850-1950. Santiago: Hueders, 2018.

Moulian, Tomás. Fracturas. De Pedro Aguirre Cerda a Salvador Allende (1938-1973). Santiago: LOM Ediciones / Universidad ARCIS, 2006.

Núñez P., Iván, La producción de conocimiento acerca de la educación escolar chilena (1907-1957). Santiago: Centro de Perfeccionamiento, Experimentación e Investigaciones Pedagógicas, 2002.

Orellana Rivera, María Isabel. El lugar de la ciencia en la educación de las mujeres. Tomo 1. Santiago: Ediciones Museo de la Educación Gabriela Mistral, 2018.

Popkewitz, Thomas S. "La historia del currículum: la educación en los Estados Unidos a principios del siglo XX, como tesis cultural acerca de lo que el niño es y debe ser". Profesorado. Revista de Currículum y Formación del Profesorado 11.3 (2007): 1-13.

Reyes J., Leonora. "Escuela pública y sistema escolar: transformaciones históricas y proyecciones”. Docencia 44 (2011): 48-63.

Rubio, Graciela y otros. "La experimentación pedagógica territorial y la democratización del sistema educativo. Lecciones del Plan Experimental de Educación Rural de San Carlos (1944-1947)". Ensaio: Avaliação e Políticas Públicas em Educação 27.102 (2019): 88-107. DOI: 10.1590/s010440362018002701488. 
Ruiz Schneider, Carlos. De la República al mercado. Ideas educacionales y política en Chile. Santiago: LOM Ediciones, 2010.

Stabili, María Rosaria. "La res-pública de las mujeres". Historia política de Chile, 1810-2010. Tomo 1. Eds. Iván Jaksic y Juan Luis Ossa. Santiago: Fondo de Cultura Económica / Universidad Adolfo Ibáñez, 2017.

Torres Carrillo, Alonso. "Prácticas educativas en movimientos sociales de América Latina”. Folios 46 (2017): 3-14. DOI: 10.17227/01234870.46folios3.14.

Valdivia Ortiz de Zárate,Verónica. La milicia republicana. Los civiles con armas, 19321936. Santiago: Dirección de Bibliotecas, Archivos y Museos, 1992. 